\title{
Genetic diseases and information to relatives: practical and ethical issues for professionals after introduction of a legal framework in France
}

\author{
Diane d'Audiffret Van Haecke ${ }^{1} \cdot$ Sandrine de Montgolfier $\mathbb{B}^{2,3}$
}

Received: 16 June 2017 / Revised: 15 January 2018 / Accepted: 17 January 2018 / Published online: 27 February 2018

(c) European Society of Human Genetics 2018

\begin{abstract}
Health professionals have a role to play in assisting patients to communicate genetic information to their relatives. In France, a specific unique legal framework has been implemented concerning this issue. We questioned professionals about their practice and how it has evolved in this new frame. The French law has opted to lay responsibility for disclosure on the person concerned by a positive test result, without totally excluding some responsibility on the part of the professionals involved, in the information to be disclosed and in the transmission of the information if a patient refuses to do it themselves (indirect disclosure). We designed and validated an online survey to be sent out to healthcare professionals to explore their practice and how they went about implementing the legal provisions. We also sought to determine how healthcare professionals dealt with a patient's refusal to disclose information to their relatives, and whether the legal framework was helpful. We carried out a statistical analysis of the responses to questionnaires to interpret the results by professional category, field of medicine and genetic disorder. The results show that professionals agreed on the relevance of disclosure to relatives. However, they show a range of practices and varying representations of the genetic issue in the framework of disclosure to relatives according to their medical field, their role in the health system and their own interpretations. They indicated a lack of resources, raised some ethical issues and put forward some arguments against contacting relatives themselves.
\end{abstract}

\section{Introduction}

The familial nature of genetic diagnosis raises the question of how far genetics changes the scope of medical

These authors contributed equally: Diane d'Audiffret Van Haecke, Sandrine de Montgolfier.

Diane d'Audiffret Van Haecke

diane.daudiffret@upforhu.org

Sandrine de Montgolfier

sandrine.demontgolfier@u-pec.fr

1 LIPHA Paris-Est, Université Paris-Est Créteil Val-de-Marne, Créteil, France

2 Institut de Recherche Interdisciplinaire sur les enjeux Sociaux (IRIS), UMR 8156 CNRS - 997 Inserm-EHESS-UP 13, UFR SMBH 74 rue Marcel-Cachin, 93017 Bobigny Cedex 33, Créteil, France

3 Université Paris Est Créteil (UPEC), Créteil, France information [1, 2]. For some health disorders of genetic origin, the disclosure of information to relatives allows preventive or care measures to be taken, and enables persons affected to make decisions about their own and their offspring's health. However, the process of communicating genetic information has been shown to be challenging, and it is often uncertain whether family members have been informed [3]. Genetic healthcare professionals (HCP) have a role to play in assisting families to communicate, because of their understanding of the familial implications of genetic diagnosis [4]. This understanding confers a professional duty to discuss with the consulting patient which family members are at risk and why, and an ethical duty to encourage these patients to communicate information about the genetic diagnosis to family members [5]. Numerous studies have investigated the attitudes of professionals confronted with the possible need to breach confidentiality, if a patient does not want to disclose information to family members [6-8], or have investigated professionals' practices concerning disclosure of genetic information within families during and after genetic counselling [1, 5, 9-11]. We set 
Table 1 Main changes in the French legal framework for the disclosure of genetic information to kin since 2011

French legal framework for the disclosure of genetic information to kin (Public Health Code: L.1131-1-2)

- Patient is now legally bound to inform collateral relatives.

- Genetic counselling added to the existing justifications: genetic conditions that are serious, and treatable and preventable.

- Disclosure can be delegated to a health care professional (standardtemplate letter).

out to study this question in a specific French context, where a legal framework has been put in place. In 2011, the law concerning disclosure of information to kin underwent three major changes (Table 1) [12].

The law provided for the implementation of a specific procedure for the disclosure of genetic information to family members. The detection of any serious disease via DNA testing legally binds patients to inform their relatives about genetic risks whenever it is relevant for their health, for instance, in the case of a severe genetic anomaly that is treatable or preventable, including through genetic counselling. The patient can opt for either:

1. Direct disclosure to relatives: the patient informs their relatives themselves, and the HCP's role is restricted to delivering information to the patient concerning this procedure of disclosure to kin before and after the test, or

2. Indirect disclosure to relatives: the HCP informs the family members, with the patient's prior consent, if the latter does not want to know the genetic test result or inform their family themselves. The HCP sends this information by letter to the family members, and invites them to contact a genetic counsellor, who will have obtained necessary information from the initial prescribing physician (Fig.1).

France is one of the few countries in the world to have such an explicit legal framework (described in Fig. 1) [9, 13]. We note that during the revision of the law in Parliament, 'genetic counselling' was added to 'preventive measures or treatment' at the end of the debate in an amendment. We were interested in the impact of this addition: has the list of pathologies concerned grown or not since this new provision came into force, and what do HCPs think about it?

In this light, we questioned French medical genetics professionals about their practice and how it had evolved in this new legal framework. We investigated (i) their practice in disclosing information to relatives, (ii) the justifications for disclosure of information to relatives, (iii) any differences in how these issues were perceived among different professions and fields of medicine, and (iv) what healthcare professionals required to be able to implement the legal
Direct disclosure to relatives by the patient Indirect disclosure by the Health Care Professional (HCP)

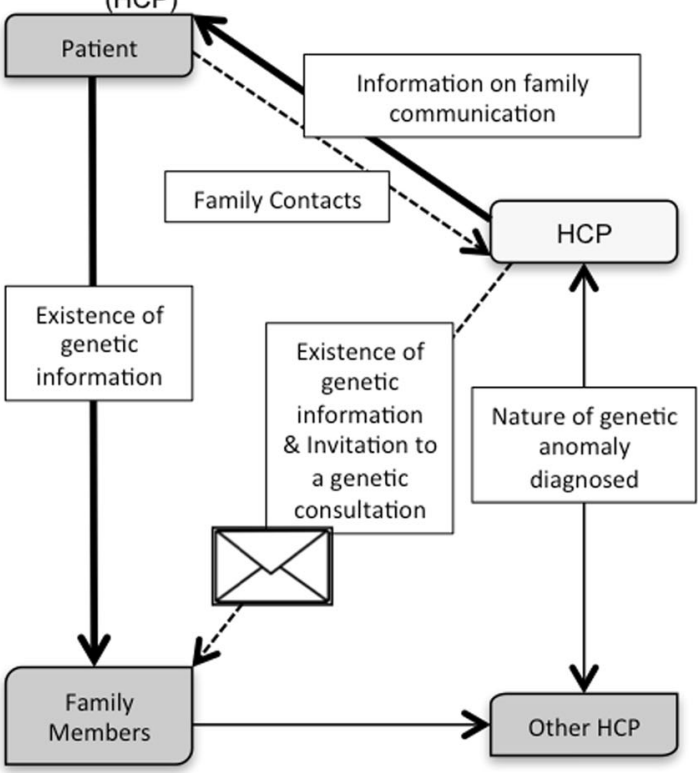

Conditions:

-Diagnosis of a serious genetic anomaly tractable of preventive measures or treatment, including genetic counselling

- Information on the procedure given by the HCP before the test

-Indirect disclosure if the patient does not want to inform their family members themselves or does not want to know the diagnosis, and if the patient gives the family contacts

Fig. 1 Genetic information to family members in French law (Public Health Code: L.1131-1-2)

provisions through the different steps in the care pathway, from fostering awareness to following up family disclosure and its outcome. We also sought to determine through the survey how healthcare professionals dealt with a patient's refusal to disclose information to their relatives, and whether the new legal framework was helpful in resolving this issue.

\section{Methods}

We designed and validated an online survey to be sent out to healthcare professionals. The design and validation were achieved in three stages:

(i) A pre-survey using semi-structured interview with 12 geneticists, clinicians and genetic counsellors was conducted in 2012 to identify areas of doubt concerning disclosure of information to relatives in the context of the new legal framework [1].

(ii) The points identified in the pre-survey were validated, together with the wording of the questionnaire, by groups of professionals. 
Table 2 Breakdown of participants

\begin{tabular}{|c|c|c|c|c|c|}
\hline & Clinical geneticist & Clinical non-geneticist & Genetic counsellor & Psychologist & Total \\
\hline All \% (n) & $44.4 \%(44)$ & $10.1 \%(10)$ & $41.4 \%(41)$ & $4.0 \%(4)$ & $100 \%(99)$ \\
\hline \multicolumn{6}{|l|}{ Age (years) } \\
\hline $20-29$ & $6.8 \%(3)$ & $0.0 \%(0)$ & $56.1 \%(23)$ & $0.0 \%(0)$ & $26.3 \%(26)$ \\
\hline $30-49$ & $54.6 \%(24)$ & $30.0 \%$ (3) & $36.6 \%(15)$ & $75.0 \%(3)$ & $45.5 \%(45)$ \\
\hline $50-64$ & $34.1 \%(15)$ & $50.0 \%(5)$ & $7.3 \%(3)$ & $25.0 \%$ & $24.2 \%(24)$ \\
\hline$\geq 65$ & $4.6 \%(2)$ & $20.0 \%(2)$ & $0.0 \%(0)$ & $0.0 \%(0)$ & $4.0 \%(4)$ \\
\hline \multicolumn{6}{|l|}{ Gender } \\
\hline Male & $15.9 \%(7)$ & $20.0 \%(2)$ & $9.8 \%(4)$ & $25.0 \%(1)$ & $14.1 \%(14)$ \\
\hline Female & $84.1 \%(37)$ & $80.0 \%(8)$ & $90.2 \%(37)$ & $75.0 \%(3)$ & $85.9 \%(85)$ \\
\hline \multicolumn{6}{|l|}{ Working environment } \\
\hline Public health centre & $92.9 \%(39)$ & $57.1 \%(4)$ & $91.7 \%(33)$ & $15.4 \%(4)$ & $89.8 \%(80)$ \\
\hline Private health centre & $11.9 \%(5)$ & $14.3 \%(1)$ & $8.3 \%(3)$ & $0.0 \%(0)$ & $10.1 \%(9)$ \\
\hline Private practice & $0.0 \%(0)$ & $28.6 \%(2)$ & $0.0 \%(0)$ & $0.0 \%(0)$ & $2.2 \%(2)$ \\
\hline \multicolumn{6}{|l|}{ Working with a centre of expertise } \\
\hline Yes & $86.4 \%(38)$ & $80.0 \%(8)$ & $70.7 \%(29)$ & $75.0 \%(3)$ & $78.8 \%(78)$ \\
\hline No & $13.6 \%(6)$ & $20.0 \%(2)$ & $29.3 \%(12)$ & $25.0 \%(1)$ & $21.2 \%(21)$ \\
\hline With specific qualification in genetics & $97.7 \%(43)$ & $0.0 \%(0)$ & $97.6 \%(40)$ & $0.0 \%(0)$ & $83.8 \%(83)$ \\
\hline
\end{tabular}

These two steps were carried out in a partnership with two genetics units: an oncogenetics unit in Paris, and a unit for red blood cell diseases in Créteil. These two units dealt with genetic health disorders with widely differing consequences in very diverse populations. We were thus able to compare the viewpoints of clinical teams with different practices and so broaden the scope of the questions and validate the relevance of the questionnaire. We met the two teams twice, at a one-month interval: first, to present the project and discuss the results of the pre-survey to identify the main issues that emerged and the relevant questions; second, to discuss the first draft to validate it. We were thus able to verify its relevance and feasibility, and to correct and improve the wording of the questions asked.

(iii) After the electronic version of the questionnaire was put online, with the service Survey Monkey ${ }^{\circledR}$, we again asked the personnel of the two units to answer the questionnaire: further adjustments to the pagination were made at this stage before send-out.

The finalised questionnaire had four parts asking about:

(A) The respondent: age, sex, profession, practitioner status, healthcare field, link with a centre of expertise and competencies in genetics,

(B) What would justify the disclosure of information to relatives? We asked the respondent to name a disorder relevant to their expertise that they felt particularly relevant for family communication.
(C) Practices in disclosure of information to relatives;

(D) The respondent's knowledge of the French law modified in 2011, and how its applicability affected their practice.

The questionnaire was put online between August 2014 and February 2015. The participants were approached via professional networks, which were identified, contacted and asked to e-mail their members a presentation of the project and a call to participate. These networks were: The French Association of Genetic Counsellors, the French Human Genetics Federation, the Network of Pre-Symptomatic and Prenatal Diagnosis Centres for Late-Onset Diseases, Orphanet, the College of General Medicine, the General Practitioners Union MG France, The National Society of Internal Medicine, the Genetics and Cancer Group, Gynecomed Ile-de-France and some individual health professionals and their own networks. We cannot therefore estimate the number of persons actually approached. We asked each group or network to send out a reminder, 2 months after the first circulation.

All the fully completed questionnaires were analysed. Raw data, overall and by category, were extracted in Excel format using the online questionnaire software. Numbers and percentages were used to summarise the demographics of the participants. The company PeopleVox carried out the statistical analysis of the results by professional category, field of medicine and genetic disorder. The professionals working in several medical fields were split according to the disorder chosen in the second part of the questionnaire as corresponding most closely to their professional practice. 
Table 3a Answer according to the pathology subtype chosen as a model by participants

\begin{tabular}{|c|c|c|c|c|c|c|c|c|}
\hline & Cardiology & $\begin{array}{l}\text { Intellectual } \\
\text { disabilities }\end{array}$ & Neurology & Oncology & Pneumology & All & $\chi^{2}(/$ all $)$ & $p$ \\
\hline All $(n)$ & $9.1 \%(9)$ & $8.1 \%(8)$ & $20.2 \%(20)$ & $42.4 \%(42)$ & $13.1 \%(13)$ & $\begin{array}{l}100 \% \\
(89)\end{array}$ & & \\
\hline \multicolumn{9}{|c|}{ Does disclosing information to relatives apply to all genetic disorders? } \\
\hline Yes & $66.7 \%$ & $50.0 \%$ & $25.0 \%$ & $59.5 \%$ & $15.4 \%$ & $46.5 \%$ & & \\
\hline No & $33.3 \%$ & $50.0 \%$ & $75.0 \% *$ & $40.5 \%$ & $84.6 \% * *$ & $53.5 \%$ & 3.841 & $\begin{array}{l}0.077 * / \\
0.033 * *\end{array}$ \\
\hline \multicolumn{9}{|c|}{ Do you think the three justifications are of equal rank? } \\
\hline Yes & $44.4 \%$ & $100 \% *$ & $31.6 \% * *$ & $48.5 \%$ & $66.7 \%$ & $52.9 \%$ & 3.841 & $\begin{array}{l}0.029 * 1 \\
0.037 * *\end{array}$ \\
\hline No & $44.4 \%$ & $0.0 \%$ & $68.4 \%$ & $30.3 \%$ & $33.3 \%$ & $37.9 \%$ & & \\
\hline Don't know & $11.1 \%$ & $0.0 \%$ & $0.0 \%$ & $21.2 \%$ & $0.0 \%$ & $9.2 \%$ & & \\
\hline
\end{tabular}

Chi-squared testing was used to determine whether there were any differences between categorical variables. According to the $p$ value, the result was considered statistically significant at 95 or $90 \%$. Odds ratio was used to compare two populations. Further to the analysis of the closed questions, we processed the open-ended questions using a question-by-question analysis.

\section{Results}

Two hundred four respondents answered the questionnaire by the closure date, with 99 questionnaires fully completed (see Table 2). The average age of respondents was 30-49. For profession, academic training and competencies in genetics, we observed an uneven response pattern with $44 \%$ clinical geneticists, $10 \%$ clinical physicians but not geneticists, $41 \%$ genetic counsellors, and 5\% psychologists. Some $90 \%$ of the respondents worked in a public health centre, $79 \%$ worked in relation with a centre of expertise for the disorder concerned, and $84 \%$ held a specific qualification in genetics.

The respondents were predominantly women (86\%). This very unbalanced sex ratio occurred because most genetics counsellors in France happen to be female. We classified into six subtypes the pathologies chosen by participants as relevant for family communication and in their field of competence. The subtypes were diseases linked to cardiology (9), neurology (20), intellectual disabilities (8), oncology (42), pneumology (13), and all other pathologies (7) (see Tables 3a and 3b). We report our results under four headings: (i) applicability of disclosure to relatives, (ii) when to broach the subject of disclosure to relatives, (iii) actors, procedures and tools available for professionals to help patients inform their kin, and (iv) applicability of indirect disclosure (disclosure to relatives through the prescribing physician as provided for in the law).

\section{Applicability of disclosure to relatives}

\section{Health disorders concerned}

The HCPs all agreed on the importance of disclosing information to relatives, but diverged concerning its scope (see Table 3a): $46.5 \%$ considered that the disclosure of information to kin applied to all genetic disorders by virtue of people's right to know, and to have access to genetic counselling, genetic screening and preventive measures or care.

As justifications for disclosure to relatives, they named severity of the disorder and its impact on quality of life, access to screening, usefulness of early monitoring and access to preventive measures and care. As justifications of non-disclosure to kin, they named benign nature of the disorder, lack of preventive measures, de novo mutation and low penetrance. Depending on the pathology chosen as a model by the participants, the answer concerning the extent of disclosure of genetic information to relatives varied (see Table 3a): in neurology (75\%) and pneumology (85\%), most professionals considered disclosure not to apply to all genetic disorders, relative to the respondents as a whole.

In the population of 'geneticists' (i.e., clinical geneticists and genetic counsellors, making up $85 \%$ of the respondents), the genetic counsellors were more inclined $(56 \%)$ than the clinical geneticists $(36.4 \%)$ to assign a broad scope to information disclosure (See Table 4).

\section{Justifications for disclosure to relatives}

In 2011, access to genetic counselling was added as a justification governing the obligation to inform kin (in addition to prevention and treatment). For $53 \%$ of the respondents, this justification ranked as high as access to measures of prevention and treatment, but there were wide variations according to the pathology chosen as a model. Strikingly, 
Table 3b Answer according to the pathology subtype chosen as a model by participants (* was added to refer to a difference statistically significant between variables, we precise the Chi-squared and $\mathrm{P}$ value in the last columns)

\begin{tabular}{|c|c|c|c|c|c|c|c|c|}
\hline & Cardiology & Intellectual disabilities & Neurology & Oncology & Pneumology & All & $\chi^{2}(/$ all $)$ & $p$ \\
\hline \multicolumn{9}{|c|}{ What do you think is the best time to talk about information to kin? } \\
\hline Before the test & $88.9 \%$ & $37.5 \% *$ & $70.0 \%$ & $88.1 \%$ & $83.3 \%$ & $79.6 \%$ & \multirow[t]{2}{*}{3.841} & \multirow[t]{2}{*}{0.085} \\
\hline With the results & $33.3 \%$ & $75.0 \%$ & $45.0 \%$ & $45.2 \%$ & $58.3 \%$ & $48.0 \%$ & & \\
\hline \multicolumn{9}{|c|}{ Do you think it is feasible to talk about information to kin before the test? } \\
\hline Yes, often & $77.8 \% *$ & $42.9 \%$ & $26.3 \%$ & $52.9 \%$ & $25.0 \%$ & $45.5 \%$ & \multirow[t]{4}{*}{7.815} & \multirow[t]{4}{*}{0.002} \\
\hline Sometimes & $11.1 \%$ & $42.9 \%$ & $42.1 \%$ & $29.4 \%$ & $50.0 \%$ & $34.1 \%$ & & \\
\hline Exceptionally & $0.0 \%$ & $14.3 \%$ & $31.6 \%$ & $17.7 \%$ & $25.0 \%$ & $19.3 \%$ & & \\
\hline No, never & $11.1 \%$ & $0.0 \%$ & $0.0 \%$ & $0.0 \%$ & $0.0 \%$ & $1.1 \%$ & & \\
\hline \multicolumn{9}{|c|}{ If you have a procedure concerning information to kin, this was set up by } \\
\hline The healthcare centre & $16.7 \%$ & $40.0 \%$ & $50.0 \%$ & $70.8 \% *$ & $33.3 \%$ & $54.9 \%$ & 3.841 & 0.045 \\
\hline Yourself & $83.3 \% *$ & $60.0 \%$ & $50.0 \%$ & $29.2 \%$ & $66.7 \%$ & $45.1 \%$ & 3.841 & 0.031 \\
\hline \multicolumn{9}{|c|}{ If a patient agrees to do it by themselves, do you help them? } \\
\hline Yes, in all cases & $55.6 \%$ & $62.5 \%$ & $60.0 \%$ & $69.1 \%$ & $50.0 \%$ & $62.2 \%$ & & \\
\hline Only in some cases & $44.4 \%$ & $37.5 \%$ & $40.0 \%$ & $31.0 \%$ & $50.0 \%$ & $37.8 \%$ & & \\
\hline No & $0.0 \%$ & $0.0 \%$ & $0.0 \%$ & $0.0 \%$ & $0.0 \%$ & $0.0 \%$ & & \\
\hline
\end{tabular}

$100 \%$ of HCPs involved in intellectual disability ranked the genetic counselling justification as high as preventive measures and treatment, against $32 \%$ of specialists involved in neurological disorders. The other specialists gave intermediate but non-significant responses. Among the professional categories, the genetic counsellors were more likely $(65 \%)$ to consider it as a justification with the same rank than were the clinical geneticists (45\%) (See Table 4). Professionals with no training in disclosure to kin were 4.40 times more likely to consider the additional justification to be of equal rank $\left(\chi^{2} 3.841, p=0.012\right)$. In general, $64 \%$ of the respondents considered that the addition of this new justification modified the number of disorders concerned, and $59 \%$ considered that it changed the population concerned.

\section{How far to inform in the family}

When asked which relatives needed to be warned, $45 \%$ of the professionals stated first-degree kin (brother, sister, parents and offspring), 33\% second-degree kin (grandparents, uncle and aunt, and grandchildren) and 23\% thirddegree kin. The professionals who supported disclosure to first-degree relatives explained that they favoured a gradual propagation of the information from one relative to the next, with the possibility of identifying the persons most concerned, in particular those planning to have children. Specialists in neurological and neuromuscular disorders were 3.10 times more likely to state third-degree kin $\left(\chi^{2}\right.$ 5.991, $p$ $=0.040$ ).

\section{Is age a criterion to inform?}

Sixty-nine per cent of the respondents considered that disclosure was not appropriate at all ages, and that the person had to be able to understand the information disclosed. However, the age at which the disorder appeared was deemed relevant, and childbearing age was often a factor. Thus, in cardiology, $67 \%$ of the professionals considered that disclosure was necessary at any age (in contrast to the overall survey population).

\section{Different views on the definition of genetic counselling and implications for disclosure of genetic information to kin}

We noted in the pre-survey [1] that professionals did not all share the same definition of genetic counselling. In this survey, we used three distinct notions: support counselling, pre-conception counselling and prenatal counselling. Access to the support counselling was the main justification (86\%) for transmitting information to the family for health professionals, before prevention and early surveillance (78\%). Pre-conceptional and prenatal counselling was a major justification for professionals involved in intellectual disability or very debilitating diseases $(>80 \%)$.

We noted that the professionals indicating preconceptional genetic counselling as a major justification of disclosure to relatives were 3.3 times more likely to favour a wide disclosure to relatives of the third degree and farther $\left(\chi^{2} 5.991, p=0.011\right)$, and three times more likely to favour a wide disclosure, irrespective of age, than those not 
Table 4 Comparison between genetic counsellors and clinical geneticists

\begin{tabular}{|c|c|c|c|c|c|}
\hline$\%(n)$ & Clinical geneticists & Genetic counsellors & Total & $\chi^{2}$ & $p$ \\
\hline \multicolumn{6}{|c|}{ Disclosing information to relatives applies to all genetic disorders } \\
\hline Yes & $36.4 \%(16)$ & $56.1 \%(23)$ & $46.5 \%(46)$ & \multirow[t]{2}{*}{3.841} & \multirow[t]{2}{*}{0.068} \\
\hline No & $63.6 \%(28)$ & $43.9 \%(18)$ & $53.5 \%(53)$ & & \\
\hline \multicolumn{6}{|c|}{ Do you think the three justifications are of equal rank $?^{\mathrm{a}}$} \\
\hline Yes & $44.7 \%(17)$ & $64.9 \%(24)$ & $52.9 \%(46)$ & \multirow[t]{3}{*}{3.841} & \multirow[t]{3}{*}{0.056} \\
\hline No & $44.7 \%(17)$ & $24.3 \%(9)$ & $37.9 \%(33)$ & & \\
\hline Don't know & $10.5 \%(4)$ & $10.8 \%(4)$ & $9.2 \%(8)$ & & \\
\hline
\end{tabular}

${ }^{a}$ preventive measures, treatment and genetic counselling

stating the pre-conceptional genetic counselling as a major justification for disclosure $\left(\chi^{2} 3.841, p=0.061\right)$.

\section{When to broach the subject of disclosure to relatives}

The best time for broaching the subject of disclosure to relatives was before the diagnosis for most of the professionals (80\%) (see Table 3b). They emphasised the need for time and explanations to obtain the patient's full agreement to sharing information with relatives. Nevertheless, in a context of intellectual disability, professionals were substantially (3.32 times) less likely than the overall survey population to advocate broaching the subject 'upstream of testing', and underlined the utility of awaiting the final diagnosis, so as to approach the subject according to the disorder identified. Concerning the feasibility of providing information prior to the test as prescribed in the new law, $46 \%$ of the respondents answered it was 'often' and 34\% 'sometimes' feasible.

In cardiology (78\%), the proportion of 'often' was greater than in the other medical fields. Overall, $86 \%$ of the respondents considered that the subject of disclosure to relatives should always be broached (without waiting for the patient to bring it up). Nevertheless, among the 'nongeneticists', 50\% considered that the announcement of the diagnosis should be dissociated from the issue of disclosure to relatives, underlining the need to take the time required for the patient to accept and understand the diagnosis and its implications; they also advocated taking into account the age of the persons potentially concerned, and any relevant family difficulties.

\section{Actors, procedures and tools available for professionals on this subject}

To foster awareness among patients of the importance of disclosure to relatives, various actors were brought into play, especially psychologists (70\% of the respondents) and genetic counsellors ( $46 \%$ of the respondents). We note that the 'non-geneticists' were much less likely to call upon a psychologist (22\%), and gave priority to a genetic counsellor $(55.6 \%)$. Slightly more than half of the respondents $(54 \%)$ declared that they had defined a specific procedure to improve disclosure of genetic information to relatives, which could include dedicated times to discuss familial consequences and conditions for informing relatives; 55\% declared that the unit or the healthcare centre set it up (see Table $3 b$ ). This figure was $71 \%$ for participants in the oncology. In cardiology, by contrast, $83 \%$ of the professionals had set up this procedure themselves. When a person opted to inform their relatives personally (direct route), $62 \%$ of the professionals declared that they helped their patient 'in all cases' and 38\% 'only in some cases depending on the context of the patient (no significant difference between professions). This help consisted essentially in giving the patient information documents $(75 \%)$ and advice about the best timing of the disclosure (73\%). Referral to a support person in the unit or to a patient association was much less frequent (29 and 26\%, respectively). The documents cited by professionals were a letter drafted by the prescribing physician about the disorder, its treatment and/ or preventive measures (81\%), documents from the centre of expertise for the genetic disorder considered (62\%), and documents issued by patient associations (50\%). Only 35\% of the respondents declared that they made sure the information actually reached the family ('sometimes' $45 \%$, 'never' 20\%). Some professionals indicated that this followup was solely oral, and that it was impossible to prove that the disclosure had actually taken place.

\section{Disclosure to relatives through the HCP}

Overall, $60 \%$ of the respondents reported the refusal of some of their patients to disclose genetic information to their relatives. In a context of intellectual disabilities, all the professionals encountered such refusal $\left(\chi^{2} 3.841, p=\right.$ $0.025)$. The reasons alleged for the refusal (52 respondents) were mostly family conflicts (69\%), but also loss of contact $(31 \%)$, and fear of stigma or discrimination (13\%). 
However, $68 \%$ of these respondents also reported a reversal in patients' attitudes once they had come to terms with the situation (38\%), after family members supporting communication had been found (10\%), or as a result of psychological support (8\%). In all, $96 \%$ of the respondents knew about the French legal context for disclosure to relatives by the prescribing physicians if a person does not want to do it themselves (indirect disclosure). Sixty-six per cent considered indirect disclosure to be part of their job, and 52\% considered it feasible. The HCPs who chose a model of pathology linked to cardiology had a significantly different response concerning the legitimacy of this delegation, being 4.3 times less likely to respond positively $\left(\chi^{2} 3.841, p=\right.$ 0.276). Eighty-seven per cent of the respondents declared that they proposed this indirect route for disclosure to relatives if a patient refused. For $44 \%$ of them, the indirect route challenged medical confidentiality, the right not to know, and privacy. Similarly, 39\% pointed out the potential psychological impact of a letter, questioning its efficacy. Finally, 36\% pointed to a lack of resources, and called for more human resources (44\%), more time to listen to patients (20\%), a dedicated website (58\%) and training (38.5\%); $15 \%$ wanted appropriate legal protection.

\section{Discussion}

In the context of disclosing information to relatives, the HCP no longer has the sole function of caring for and supporting patients, but also helps to identify kin potentially at risk. The challenge of this new orientation is defining the roles for every actor. The French law has opted to lay responsibility for disclosure on the person concerned by a positive test result. Nevertheless, it does not relieve HCPs of all responsibility: they still have to explain genetic issues, familial consequences and the patient's responsibility for disclosure of genetic information to kin. In addition, if a patient does not want to disclose the genetic information to their relatives by themselves, but agrees on indirect disclosure, then the HCP has to deal with it [13]. We will now discuss our results in the light of research carried out on the place of professionals in the framework of disclosure of genetic information to relatives [8-10, 14].

The results show that professionals agreed on the relevance of disclosing genetic information to relatives. However, they showed a range of practices and varying representations of the genetic issue in the framework of disclosure to relatives. These differences result in varied opinions or interpretations concerning the applicability of the French legal provision according to their medical field, their role in the health system, and their own definition of genetic counselling.

\section{Different actors, different views on disclosure to relatives in human genetics}

The specific features of genetics take the doctor-patient relation out of the one-to-one bond and into a multidisciplinary support system involving clinical geneticists, other clinicians, genetic counsellors, psychologists and patient associations. These different actors do not all have competencies in genetics, and do not all share the same degree of awareness about the impact on families of an identified mutation. This variation can have important repercussions not only on the care and support of the patient, but also on the disclosure of genetic information to the patient's relatives. We regret the low representation of 'non-geneticists' in this study, which may reflect difficulty approaching networks of professionals less directly concerned by genetics, and less aware of the implications of genetic disorders for kin. In addition, the actors do not all share the same views on the disorders concerned by disclosure to relatives: for example, genetic counsellors were significantly more likely than clinical geneticists to assert that disclosure concerned all genetic disorders. This divergence may stem from the fact that these actors play quite distinct roles in patient care. Genetic counsellors are more narrowly focused on the mechanisms of transmission of the mutation, whereas clinicians are primarily interested in the patient's medical care $[15,16]$. As regards which relatives to inform, the professionals mostly advocated disclosure to first-degree kin, and transmission of the information from one relative on to the next. However, we observed that the 'geneticists' were more likely to favour far-reaching disclosure than 'non-geneticists'. It would seem that more professional collegiality could usefully be encouraged so that different viewpoints can be shared, and decisions made on the basis of competing priorities.

\section{Applicability of disclosure to relatives: what are the justifications?}

The most important justifications named by the HCPs were access to genetic counselling in support, prevention and threat to life. Comparing medical fields, some observed variations warrant further exploration: access to treatment was a major justification in cardiology, but not in pneumology, and was assigned ranging importance in the other medical fields, such as in oncology, where the appraisal was found to vary according to the cancer considered. These differences could reflect the differing degrees of threat to life and the known benefits of early care. The French legal framework concerns 'severe genetic abnormalities for which there exist preventive measures, including genetic counselling, or treatment. The law proposes two yardsticks for 
appraising severity: 'risk of premature death' and 'risk of severe disability, in particular the risk of a lack of autonomy in adulthood'. The appraisal of the degree of severity will take into account 'probable clinical manifestations', variability in the expression of the disorder and the current state of knowledge. The existence of 'preventive measures, including genetic counselling, and treatment' has also to be considered.

Our study shows that different professionals, according to their medical field and their competencies in genetics, differed in their evaluation of the genetic counselling as a justification for disclosing genetic information to kin. Through a subdivision of genetic counselling into support, pre-conceptional and prenatal counselling, we found that professionals had varying definitions of the role and scope of application of genetic counselling that depended on their profession. Do these differences in how the scope of genetic counselling is defined reveal different views on the utility of genetics in healthcare? This question was prompted by a correlation we observed among certain professionals: those who considered that access to pre-conceptional genetic counselling was a major justification for disclosing genetic information to relatives advocated extending disclosure to more distant relatives, and emphasised childbearing age as a factor when informing them. This may underline a difference of training among professionals concerning the impact of genetics: those least well-versed in genetics ranked genetic counselling significantly more often alongside the two other justifications (prevention and treatment). Would a clearer definition of genetic counselling allow a better appraisal of its role and scope, according to the medical field, in particular with the fast growth of new methods of sequencing and the new data that will soon be available? We have to bear in mind that the French law was originally meant to address situations that were life-threatening to relatives [17]. The question for the French law is thus: are these three justifications (prevention, genetic counselling and treatment) for disclosure of information to kin cumulative or each sufficient individually? If the genetic counselling alone could be a justification, all hereditary genetic disorders would fall within the scope of the law, even if there are no treatment or prevention measures to fight the disease. The example of Huntington's disease comes to mind: should a patient be held legally responsible if they fail to disclose the information to their relatives given that there is neither treatment nor prevention measures? Given the diversity of these situations, further thinking on the part of professionals, ethics bodies and learned societies will be needed to delimit the concrete, efficacious applicability of disclosure of genetic information to relatives in different model disorders, and so help practitioners exercise sound judgement.

\section{Disclosure to relatives in practice: needs and issues}

In this study, we report a range of approaches by health professionals to the implementation of recommendations for the disclosure of genetic information to relatives. To harmonise practice according to the disorders concerned, it could be useful to design care pathways in which each actor would be assigned a known role in this context of disclosure to relatives, and so receive appropriate training. The delivery of information by the practitioners to the kin (indirect disclosure) was deemed part of their job, and practicable by most of the respondents, but they pointed out a lack of resources, and raised some ethical issues. They felt responsible to relatives, but put forward many arguments against indirect disclosure, as shown in the study of Dheensa, which led them to favour direct disclosure [9]. Possibly, some professionals do not want to be involved in indirect information, so they will not be held responsible if the information does not get through. This issue underlies the first court cases in the United Kingdom, where the court was called to rule on whether there was a duty of care for healthcare professionals towards their patients' relatives even without the patients' agreement [18]. In the French context, even if a professional is responsible for informing their patient about their legal obligation towards their relatives, the professional cannot directly inform relatives without the patient's agreement. The legal liability would here lie with the patient who refused to inform their family either directly or indirectly, if the disease was severe, and if there existed 'prevention, including genetic counselling, or treatment measures'. The case concerned Huntington's disease: we have seen that the French legal framework is not clear about such a disease. Nevertheless, concerning patient acceptance, French HCPs observed that most patients moved on from refusal to agreement to disclose genetic information to kin as time passed, or with psychological support, or after cooperative family members were identified. For HCPs, disclosure by patients themselves seems better than by themselves for both practical and human reasons, as confirmed by several studies [11, 19]. It requires thinking about the tools that need to be made available to the patient, and their accessibility: letters and document, possibly in electronic format [14]. We note that the French law does not provide for any subsequent follow-up of disclosure. Even so, for disorders that are life-threatening and for which there are preventive measures or treatments, it may be appropriate for professionals to support the patient more closely and more individually to favour communication with the family $[5,20,21]$. The designation of a support person among the care professionals, who would help the patient perform the disclosure, could be envisaged. Patient associations, through their proximity to the families, provided their members have been appropriately trained and 
their roles in the patient's pathway clearly defined, could act as facilitators in the disclosure process [1].

Newly available technology such as very highthroughput sequencing greatly enhances our ability to identify potentially at-risk patients who require family communication. This trend requires a better definition of the conditions necessary for proper disclosure of genetic information to relatives implying commitment of all actors to ensure adequate dissemination of results when necessary $[18,23]$. We recommend the development, using model pathology, of specific procedures with a multidisciplinary decision-making process to cross-different points of view. This would enable real support and an enlightened decision by patients, who are legally responsible for informing their relatives.

\section{Conclusion}

The issue of whether to inform collateral relatives to prevent genetic condition-related risks is a major dilemma for the healthcare professionals involved. The study we have conducted concerns HCP practice concerning familial genetic information sharing. A French legal provision for disclosing relevant information to family introduces (i) a duty for persons taking a test to inform their relatives if a pathogenic variant is discovered that concerns a serious health disorder for which treatments, prevention and/or genetic counselling exist, and (ii) the possibility for such persons to inform their relatives indirectly by means of a confidential letter addressed to those relatives by healthcare professionals. This study is an important contribution to exploring a uniquely binding legal framework. HCPs all agree on the relevance of disclosing genetic information to relatives, but are uncertain about the limits of the legal framework. The addition of genetic counselling to the legal justifications for disclosure of genetic information to kin is not viewed homogeneously according to the professionals, their speciality and their level of training in genetics. As a justification, it extends the scope of the law (extending those pathologies concerned) and raises important ethical questions when there is no prevention or treatment. We recommend (i) due emphasis on the legal obligation to inform family in cases of severe genetic diseases for which there are preventive measures or treatment, and (ii) specification in the legal framework of available genetic counselling as an obligatory support, but not as a sufficient justification on its own to oblige patients to inform their families. Possible indirect disclosure to relatives by the physician when a patient does not want to know their results or does not want to inform their relatives themselves is a step that HCPs consider part of their job, but which requires new resources.
Acknowledgements This project was supported by ABM (AAP2013), INCa for the project 'Familial disclosure in human genetics: implications and implementation in case of familial genetic disorders' (Grant no. 2013-130) and Canceropole-Ile-de-France. We thank all the healthcare professionals who took part in this study.

\section{Compliance with ethical standards}

Conflict of interest The authors declare that they have no conflict of interest.

\section{References}

1. D'Audiffret Van Haecke D, de Montgolfier S. Genetic test results and disclosure to family members: qualitative interviews of healthcare professionals' perceptions of ethical and professional issues in France. J Genet Couns. 2016;25:483-94. https://doi.org/ 10.1007/s10897-015-9896-7.

2. Weil-Dubuc P-L, Les servitudes du droit de savoir, La Vie Des Idées, 2013. Retrieved from http://www.laviedesidees.fr/Lesservitudes-du-droit-de-savoir.html.

3. Gaff CL, Clarke AJ, Atkinson P, et al. Process and outcome in communication of genetic information within families: a systematic review. Eur J Human Genet. 2007;15:999-1011. https:// doi.org/10.1038/sj.ejhg.5201883.

4. Resta RG. Defining and redefining the scope and goals of genetic counseling. Am J Med Genet Part C, Semin Med Genet. 2006;142C:269-75. https://doi.org/10.1002/ajmg.c.30093.

5. Forrest LE, Delatycki MB, Skene L, Aitken M. Communicating genetic information in families-a review of guidelines and position papers. Eur J Human Genet. 2007;15:612-8. https://doi. org/10.1038/sj.ejhg.5201822.

6. Barnoy S, Tabak N. Israeli nurses and genetic information disclosure. Nurs Ethics. 2007;14:280-94. https://doi.org/10.1177/ 0969733007075862.

7. Godard B, Hurlimann T, Letendre M, Egalité N. Guidelines for disclosing genetic information to family members: from development to use. Fam Cancer. 2006;5:103-16. https://doi.org/10. 1007/s10689-005-2581-5.

8. Stol YH, Menko FH, Westerman MJ, Janssens RMJPA. Informing family members about a hereditary predisposition to cancer: attitudes and practices among clinical geneticists. J Med Ethics. 2010;36:391-5. https://doi.org/10.1136/jme.2009.033324.

9. Dheensa S, Fenwick A, Shkedi-Rafid S, Crawford G, Lucassen A. Health-care professionals' responsibility to patients' relatives in genetic medicine: a systematic review and synthesis of empirical research. Genet Med. 2016;18:290-301. https://doi.org/10.1038/ $\operatorname{gim} .2015 .72$.

10. Mendes Á, Paneque M, Sousa L, Clarke A, Sequeiros J. How communication of genetic information within the family is addressed in genetic counselling: a systematic review of research evidence. Eur J Human Genet. 2016;24:315-25. https://doi.org/ 10.1038/ejhg.2015.174.

11. Derbez B, Pauw A, de, Stoppa-Lyonnet D, Montgolfier Sde. Supporting disclosure of genetic information to family members: professional practice and timelines in cancer genetics. Fam Cancer. 2017;16:447-57. https://doi.org/10.1007/s10689-017-9970-4.

12. Law No. 2011-814 dated 7 July 2011 (art. 2) Code de la santé publique. L1131-1, JORF, 2011.

13. Farnos C, Battistuzzi L, Mendes Á, et al. Disclosing genetic information to family members: a comparativelaw study of the legal regimes applicable to patients' and health professionals' liability. Poster at the ESHG meeting at Barcelone 2016, SPAIN. 
Retrieved from https://www.eshg.org/fileadmin/www.eshg.org/ conferences/2016/downloads/ESHG2016_Abstracts_final.pdf.

14. Forrest LE, Delatycki MB, Curnow L, Skene L, Aitken M. Genetic health professionals and the communication of genetic information in families: practice during and after a genetic consultation. Am J Med Genet. 2010;152A:1458-66. https://doi.org/ 10.1002/ajmg.a.33385.

15. Cordier C, Taris N, De Pauw A, Sobol H, Philip N, Voelckel M-A. French professionals in genetic counselor careers. J Genet Couns. 2013;22:844-8. https://doi.org/10.1007/s10897-013-9599-x.

16. Lenk C, Frommeld D. Different concepts and models of information for family-relevant genetic findings: comparison and ethical analysis. Med Health Care Philos. 2015;18:393-408. https://doi.org/10.1007/s11019-015-9638-5.

17. Binet J-R, Leonetti J. La réforme de la loi bioéthique commentaire et analyse de la loi no. 2011-814 du 7 juillet 2011 relative à la bioéthique. Paris: LexisNexis; 2012.

18. ABC v St George's Healthcare NHS Trust. EWHC 1394 (QB), MHLO 39. 2015. http://www.bailii.org/ew/cases/EWHC/QB/ 2015/1394.html.

19. Dheensa S, Fenwick A, Lucassen A. Approaching confidentiality at a familial level in genomic medicine: a focus group study with healthcare professionals. BMJ Open. 2017;7:e012443 https://doi. org/10.1136/bmjopen-2016-012443.

20. Suthers GK, Armstrong J, McCormack J, Trott D. Letting the family know: balancing ethics and effectiveness when notifying relatives about genetic testing for a familial disorder. J Med Genet. 2006;43:665-70. https://doi.org/10.1136/jmg.2005. 039172.

21. Kerzin-Storrar L, Wright C, Williamson PR, et al. Comparison of genetic services with and without genetic registers: access and attitudes to genetic counselling services among relatives of genetic clinic patients. J Med Genet. 2002;39:e85.

22. Wouters RHP, Bijlsma RM, Ausems MGEM, van Delden JJM, Voest EE, Bredenoord AL. Am I my family's keeper? disclosure dilemmas in next generation sequencing. Human Mutat. 2016;37:1257-62. https://doi.org/10.1002/humu. 23118.

23. Ani Kardashian, Julia Fehniger, Jennifer Creasman, Eleanor Cheung, Mary Stanley Beattie, (2012) A Pilot study of the Sharing Risk Information Tool (ShaRIT) for Families with Hereditary Breast and Ovarian Cancer Syndrome. Hereditary Cancer in Clinical Practice 10 (1) 